\title{
Dabigatran reversal with idarucizumab in a patient undergoing heart transplantation: first European report
}

\author{
António Tralhão ${ }^{* *}$, Carlos Aguiarr', Jorge Ferreira ${ }^{1}$, Maria José Rebocho², Emília Santos ${ }^{3}$, Dinis Martins ${ }^{3}$ \\ and José Pedro Neves ${ }^{2}$
}

\begin{abstract}
Background: Dabigatran is a direct thrombin inhibitor with a favorable effectiveness and safety profile when compared to vitamin $\mathrm{K}$ antagonists, both in randomized trials and real world registries of atrial fibrillation patients. Yet, physicians' fear of high bleeding risk scenarios in daily clinical practice still precludes a more widespread use of oral anticoagulation. We hereby report a successful case of dabigatran reversal with the novel monoclonal antibody fragment idarucizumab in a patient undergoing heart transplantation.
\end{abstract}

Case presentation: A 45-year old male patient on dabigatran for atrial fibrillation thromboprophylaxis was enlisted for heart transplantation due to end-stage ischemic heart failure. Upon donor availability and suitability and following the last intake of the drug $12 \mathrm{~h}$ previously, activated partial thromboplastin time was measured and found to be elevated. After general anesthesia and before extracorporeal circulation, idarucizumab was administered as two boluses of $2.5 \mathrm{~g}$. Orthotopic heart transplantation ensued under full heparinization and cardiopulmonary bypass. Total chest tube output was $1125 \mathrm{~mL}$ after 3 days and 4 units of fresh frozen plasma and one platelet pool were administered in the operating room without further need for blood products. The post-operative period was uneventful.

Conclusions: Idarucizumab was associated with an effective hemostasis in the setting of heart transplantation. Dabigatran may be considered as an alternative to vitamin $\mathrm{K}$ antagonists in heart transplant candidates with an indication for oral anticoagulation.

Keywords: Dabigatran, Idarucizumab, Heart transplantation

\section{Background}

Atrial fibrillation (AF) is estimated to affect almost 6 million Europeans and the overwhelming majority will have an indication for oral anticoagulation [1]. Notably, oral anticoagulation is the most effective measure to reduce the risk of thromboembolic events and their devastating sequelae [2]. In recent years, stroke and systemic embolism prevention in $\mathrm{AF}$ patients has met a new era after the publication of the landmark trials of the non-vitamin $\mathrm{K}$ dependent oral anticoagulants (NOACs) [3-6]. Evidence from both randomized studies and real-world registries have consistently demonstrated at least an antithrombotic

\footnotetext{
* Correspondence: atralhao@gmail.com

'Department of Cardiology, Hospital de Santa Cruz, Centro Hospitalar de Lisboa Ocidental, Av. Professor Doutor. Reinaldo dos Santos, 2790-134 Carnaxide, Portugal

Full list of author information is available at the end of the article
}

equipoise and less bleeding complications against vitamin $\mathrm{K}$ antagonists (VKA) [7, 8]. Another advantage shared by all NOACs is pharmacokinetic predictability, obviating the need for routine laboratory control and leading to greater patient comfort.

However, the lack of an antidote capable of restoring hemostasis in case of life-threatening bleeding or nondeferrable surgery after recent drug exposure still represented a major drawback for most of these agents [9]. In an effort to meet this unfulfilled need, a novel monoclonal antibody fragment was recently developed as an antidote for dabigatran, the first approved NOAC [10]. In a recent prospective study performed in patients with life threatening bleeding or the need for an urgent invasive procedure, idarucizumab promptly reverted the effect of dabigatran [11]. 
Nevertheless, each procedure bears its own bleeding risk and it is uncertain whether data from this small preliminary cohort study holds true in specific patient subsets. We hereby report a case of successful dabigatran reversal with idarucizumab in a patient undergoing heart transplantation.

\section{Case description}

A 45-year-old male blood type $\mathrm{A}^{+}$was enlisted for heart transplantation in December 2016 after entering stage D ischemic heart failure. His past history included a large anterior myocardial infarction (MI) in 2015 treated with alteplase and stent placement to the left anterior descending artery, abandoned smoking habits (60 pack-years), hypertension and bouts of self-terminating paroxysmal AF diagnosed during his various admissions for decompensated heart failure (left ventricular ejection fraction of 23\%). Since he had a $\mathrm{CHA}_{2} \mathrm{DS}_{2}$-VASc of 3 [(Congestive heart failure, Hypertension, Age (doubled), Diabetes, Stroke/Transient ischemic attack/systemic thromboembolism (doubled), VAscular disease, Sex category), expected annual stroke rate of 3.2\%], he was initially put on oral anticoagulation with rivaroxaban $20 \mathrm{mg}$ (milligrams) once daily. His remaining medication was composed of carvedilol $6.25 \mathrm{mg}$ bid (bis in die), ramipril $2.5 \mathrm{mg}$ od (omni die), spironolactone $25 \mathrm{mg}$ od, furosemide $40 \mathrm{mg}$ bid, metolazone $10 \mathrm{mg}$ od and atorvastatin $40 \mathrm{mg}$ od. Laboratory evaluation showed a creatinine of $1.0 \mathrm{mg}$ per deciliter $(\mathrm{dL})$ [creatinine clearance of 119 milliliters $(\mathrm{mL})$ per minute (min) by Cockroft-Gault's formula] and a Nterminal-proB-type natriuretic peptide of 2566 picograms (pg) per $\mathrm{mL}$, with no other relevant abnormalities. After being accepted for heart transplantation, he was given a priority of 6 out of 7, the highest for outpatients, 1-5 being reserved for inpatients in the waiting list. Following availability of idarucizumab at our institution, he was switched from rivaroxaban to dabigatran $110 \mathrm{mg}$ bid, which was started $24 \mathrm{~h}(\mathrm{~h})$ after the last dose of rivaroxaban.

On the 5th February 2017, a potential donor in brain death was deemed suitable for organ procurement. After a negative crossmatch and direct surgical inspection, the heart was excised at $11 \mathrm{~h} 45 \mathrm{~min}$ and arrived at our institution, where the receiver was waiting in the operating room under general anesthesia. His laboratory workup $6 \mathrm{~h}$ previously showed a hemoglobin of $14.6 \mathrm{~g}$ per dL, platelet count of 104. 000 per microliter, an activated partial thromboplastin time (aPTT) of $39.6 \mathrm{~s}(\mathrm{~s})$ [1.35 times the mean reference value (reference range: $23-38 \mathrm{~s}$ )], a prothrombin time (PT) of $18.5 \mathrm{~s}$ (reference $<14 \mathrm{~s}$ ) and a fibrinogen of $4.2 \mathrm{~g}$ per liter (L) (reference range: $1.50-4 \mathrm{~g}$ per L). As the patient had taken the last dose of dabigatran in the night before $(12 \mathrm{~h}$ previously) and both dilute thrombin time (dTT) and ecarin time (ET) were unavailable at the time at our institution, prompt restoration of hemostasis was considered necessary so that heart transplantation could be safely performed.
After median sternotomy (16h15min) and pericardiotomy, cannulation of the aorta and both caval veins, idarucizumab was administered as two consecutive boluses of $2.5 \mathrm{~g}$ and the patient was cooled to $25^{\circ}$ Celsius under nasopharyngeal monitoring. $50 \mathrm{mg}$ of tranexamic acid were also administered intravenously, followed by a continuous infusion of $90 \mathrm{mg}$ per hour during $2 \mathrm{~h} 30 \mathrm{~min}$. First measured activated clotting time [(ACT), minutes after idarucizumab administration) was $147 \mathrm{~s}$ (reference range 80-160 s). After an intravenous bolus of 27000 international units [(IU), 300 per $\mathrm{kg}$ of body weight] of non-fractionated heparin targeting an ACT between 400 and $480 \mathrm{~s}$ (together with priming of the extracorporeal circuit with $5000 \mathrm{IU}$ ), cardiopulmonary bypass $(\mathrm{CPB})$ was started and orthotopic heart transplantation ensued. Peak ACT was $>1000 \mathrm{~s}$ during $\mathrm{CPB}$ and $146 \mathrm{~s}$ after protamine (1 mg per $10 \mathrm{IU}$ of heparin) and just before $\mathrm{CPB}$ exit. Hemoglobin was $14.5 \mathrm{~g}$ per dL pre-CBP and $11.9 \mathrm{~g}$ per $\mathrm{dL}$ post-CPB. Total blood products given during $\mathrm{CBP}$ amounted to 1 pool of platelets, 4 units of fresh frozen plasma and $1000 \mathrm{~mL}$ of recovered blood from the surgical field via Cellsaver ${ }^{\circ}$.

The patient was easily weaned off $\mathrm{CPB}$ and was transferred to the Intensive Care Unit (ICU) under dopamine [2 micrograms $(\mu \mathrm{g})$ per kilogram $(\mathrm{kg})$ per $\mathrm{min}$ ] and isoproterenol $(0.04 \mu \mathrm{g}$ per $\mathrm{kg}$ per $\mathrm{min})$. Cardiopulmonary bypass time was $120 \mathrm{~min}$, aortic cross clamping time was $75 \mathrm{~min}$ and cold ischemia time was $165 \mathrm{~min}$.

The following post-operative course was uneventful. Total pericardial and pleural drain yield was $300 \mathrm{~mL}$ by the 6th post-operative hour (baseline $300 \mathrm{~mL}$ in each drain after sternal closure) and total drainage was $1125 \mathrm{~mL}$. No further blood products were administered.

\section{Discussion and conclusions}

A normally functioning clotting system capable of contributing to an efficacious hemostasis is a fundamental prerequisite for performing major surgery. Understandably, quickly offsetting the effect of any anticoagulant would be desirable to minimize the occurrence of bleeding.

Dabigatran etexilate is a direct thrombin inhibitor, available in 75, 110 and $150 \mathrm{mg}$ dosages in Europe and is currently approved for thromboprophylaxis in AF patients and in primary and secondary venous thromboembolism prophylaxis [12]. Peak plasma levels and full anticoagulant activity are attained following $2 \mathrm{~h}$ after the first drug intake, with a bioavailability of $3-7 \%$ after conversion to dabigatran and a $35 \%$ binding fraction to plasma proteins [13]. Metabolism occurs via the efflux transporter P-gp and the drug is not a substrate, inhibitor or inducer of CYP450 enzymes [13]. The drug undergoes predominant (80\%) renal elimination [13]. Under normal kidney function, dabigatran half-life is 12-17 h but can reach $28 \mathrm{~h}$ in cases of severe renal impairment [13]. Unlike VKA, the level of anticoagulation 
cannot be quantitatively assessed by standard parameters such as TP or international normalized ratio, aPTT or ACT but can be achieved through other non-routinely performed tests such as dTT, which is extremely sensitive to dabigatran [14]. ET also shows a linear relation with increasing dabigatran concentrations and can be used alternatively [15]. In our center, both of these tests were unavailable. Nevertheless, given the pharmacokinetics of the drug and our patient's estimated creatinine clearance, a relevant anticoagulant effect at the time of surgery was very likely, since a $12 \mathrm{~h}$ time interval corresponds to the drug's steady-state trough level [16]. This may be further supported by an elevated aPTT ( $39.6 \mathrm{~s}$ or 1.35 times the mean reference value). Although the precise plasmatic level of dabigatran is not inferable from aPTT, the fact that it was prolonged is also considered to be a reliable surrogate for measurable drug levels [14]. Finally, and although documenting dabigatran anticoagulant activity seems reasonable, such strategy is not free of risks, as it may imply the notion that these tests are an indispensable pre-requisite to antidote utilization in everyday clinical practice. In accordance, idarucizumab's summary of product characteristics does not mandate prior laboratory confirmation of anticoagulant activity [17].

As opposed to VKA, the lack of a fast-acting antidote capable of quickly restoring hemostasis in a case of major bleeding or urgent surgery was viewed by many as an Achilles heel that could hinder a more wider use of the drug when clinically appropriate. Due to dabigatran's mechanism of action, usual antithrombotic effect reducing strategies such as concentrate of prothrombinic factors are less efficacious as thrombin remains inhibited [13]. Furthermore, alternative strategies such as removal by hemodialysis, although possible, are time consuming due to dabigatran's large volume of distribution and not free of access-related vascular complications [18]. Idarucizumab is a humanized monoclonal antibody fragment with an affinity for dabigatran that is 350 times higher than that of thrombin, promptly neutralizing dabigatran [10]. In the RE-VERSE AD trial, 90 patients taking dabigatran (64\% of which under the $110 \mathrm{mg}$ dosage) and presenting with major blood loss (group A, $n=51$ ) or requiring urgent surgery (group $\mathrm{B}, n=39$ ) received $5 \mathrm{~g}$ of idarucizumab as two $50 \mathrm{~mL}$ bolus given no more than 15 min apart. In group B, dTT and ET normalized in 93 and $88 \%$ of patients within minutes after the administration of idarucizumab [11].

Our case is among the first to report the reversal of dabigatran in the setting of urgent heart transplantation and the first, to the best of our knowledge, in a European country [19]. This patient would be excluded from the RE-LY trial due to foreseeable surgery in 3 months at the time of randomization [3].
Furthermore, in RE-VERSE-AD preliminary results, urgent surgery procedures did not include heart transplantation [11]. Notwithstanding, idarucizumab seems to constitute a useful, rapidly acting and effective dabigatran reversal agent in patients undergoing heart transplantation with recent drug exposure. The possibility of antagonizing dabigatran should be taken into consideration when weighing the risks and benefits of prescribing an oral anticoagulant to heart transplant candidates.

\section{Abbreviations}

ACT: Activated clotting time; AF: Atrial fibrillation; aPTT: Activated partial thromboplastin time; bid: bis in die; $\mathrm{CHA}_{2} \mathrm{DS}_{2}-\mathrm{VASc}$ : Congestive heart failure, Hypertension, Age (doubled), Diabetes, Stroke/Transient ischemic attack/ systemic thromboembolism (doubled), VAscular disease, Sex category; CPB: Cardiopulmonary bypass; dL: Deciliter; dTT: Dilute thrombin time; ET: Ecarin time; g: Grams; ICU: Intensive care unit; IU: International units; Kg: Kilograms; L: Liter(s); mg: Milligrams; MI: Myocardial infarction; min: Minute(s); mL: Milliliter(s); NOAC: Non-vitamin K dependent oral anticoagulants; od: omni die; pg: Picograms; PT: Prothrombin time; s: Seconds; VKA: Vitamin K antagonists; $\mu \mathrm{g}$ : Micrograms

\section{Acknowledgements}

Not applicable.

\section{Funding}

The authors declare they received no funding to support the elaboration of this manuscript.

\section{Availability of data and materials}

All patient clinical data and information provided in the manuscript is stored electronically and can be consulted if deemed necessary.

\section{Author's contributions}

AT was responsible for data acquisition and drafting the manuscript. CA, JF, MJR, ES and DM revised the manuscript critically for important intellectual content. JPN was the senior surgeon who performed the heart transplantation surgery and revised the manuscript critically for important intellectual content. All authors read and approved the final manuscript.

Ethics approval and consent to participate

The ethics committee approval was waived.

Consent for publication

Patient informed consent was obtained prior to manuscript submission.

\section{Competing interests}

The authors declare that they do not possess competing interests.

\section{Publisher's Note}

Springer Nature remains neutral with regard to jurisdictional claims in published maps and institutional affiliations.

\section{Author details}

'Department of Cardiology, Hospital de Santa Cruz, Centro Hospitalar de Lisboa Ocidental, Av. Professor Doutor. Reinaldo dos Santos, 2790-134 Carnaxide, Portugal. ${ }^{2}$ Department of Cardiothoracic Surgery, Hospital de Santa Cruz, Centro Hospitalar de Lisboa Ocidental, Av. Professor Doutor. Reinaldo dos Santos, 2790-134 Carnaxide, Portugal. ${ }^{3}$ Department of Cardiology, Hospital do Divino Espírito Santo, Av. D. Manuel I, 9500-370 Ponta Delgada, Portugal. 
Received: 5 April 2017 Accepted: 14 July 2017

\section{Published online: 05 September 2017}

\section{References}

1. Pillarisetti J, Lakkireddy D. Atrial fibrillation in Europe: state of the state in disease management! Eur Heart J. 2014;35:3326.

2. Kirchhof P, Benussi S, Kotecha D, Ahlsson A, Atar D, Casadei B, et al. 2016 ESC guidelines for the management of atrial fibrillation developed in collaboration with EACTS. Eur Heart J. 2016;37:2893-962.

3. Connolly SJ, Ezekowitz MD, Yusuf S, Eikelboom J, Oldgren J, Parekh A, et al. Dabigatran versus warfarin in patients with atrial fibrillation. $\mathrm{N}$ Engl J Med. 2009;361:1139-51.

4. Granger CB, Alexander JH, McMurray JJV, Lopes RD, Hylek EM, Hanna M, et al. Apixaban versus warfarin in patients with atrial fibrillation. N Engl J Med. 2011:365:981-92.

5. Patel MR, Mahaffey KW, Garg J, Pan G, Singer DE, Hacke W, et al. Rivaroxaban versus warfarin in nonvalvular atrial fibrillation. N Engl J Med. 2011;365:883-91.

6. Giugliano RP, Ruff CT, Braunwald E, Murphy SA, Wiviott SD, Halperin JL, et al Edoxaban versus warfarin in patients with atrial fibrillation. N Engl J Med. 2013;369:2093-104.

7. Carmo J, Moscoso Costa F, Ferreira J, Mendes M. Dabigatran in real-world atrial fibrillation. Meta-analysis of observational comparison studies with vitamin K antagonists. Thromb Haemost. 2016;116:754-63.

8. Ruff CT, Giugliano RP, Braunwald E, Hoffman EB, Deenadayalu N, Ezekowitz $M D$, et al. Comparison of the efficacy and safety of new oral anticoagulants with warfarin in patients with atrial fibrillation: a meta-analysis of randomised trials. Lancet. 2017;383:955-62.

9. Vílchez JA, Gallego P, Lip GYH. Safety of new oral anticoagulant drugs: a perspective. Ther Adv Drug Saf. 2014;5:8-20.

10. Schiele F, van Ryn J, Canada K, Newsome C, Sepulveda E, Park J, Nar H, Litzenburger T. A specific antidote for dabigatran: functional and structural characterization. Blood. 2013;121:3554-62

11. Pollack CV, Reilly PA, Eikelboom J, Glund S, Verhamme P, Bernstein RA, et al. N Engl J Med. 2015;373:511-20.

12. Boehringer Ingelheim. Pradaxa product information. 2015. Available from: http://www.ema.europa.eu/ema/index.jsp?curl=pages/medicines/human/ medicines/000829/human_med_000981.jsp.

13. Stangier J. Clinical pharmacokinetics and pharmacodynamics of the oral direct thrombin inhibitor Dabigatran Etexilate. Clin Pharmacokinet. 2008;47:285-95.

14. Ryn J Van, Grottke O, Spronk H. Measurement of dabigatran in standardly used clinical assays, whole blood viscoelastic coagulation, and thrombin generation assays. Clin Lab Med. 2014; 34: 479-501.

15. Hawes EM, Deal AM, Funk-Adcock D, Gosselin R, Jeanneret C, Cook AM, et al. Performance of coagulation tests in patients on therapeutic doses of dabigatran: a cross-sectional pharmacodynamic study based on peak and trough plasma levels. J Thromb Haemost. 2013;11:1493-502.

16. Liesenfeld K-H, Lehr T, Dansirikul C, Reilly PA, Connolly SJ, Ezekowitz MD, et al. Population pharmacokinetic analysis of the oral thrombin inhibitor dabigatran etexilate in patients with non-valvular atrial fibrillation from the RE-LY trial. J Thromb Haemost. 2011;9:2168-75.

17. Boehringer Ingelheim. Praxbind product information. 2017. Available from: http://www.ema.europa.eu/ema/index.jsp?curl=pages/medicines/human/ medicines/003986/human_med_001938.jsp\&mid=WC0b01ac058001d124.

18. Ferreira J, Ferreira D, Viana-Baptista M, Bettencourt $P$, Cernadas $R$, Crespo F. Dabigatran for stroke prevention in nonvalvular atrial fibrillation: answers to challenging "real-world" questions. Thrombosis. 2012;2012:867121.

19. Rimsans J, Rhoten M, Sylvester K, Singh SK, Connors JM. Idarucizumab for urgent reversal of dabigatran for heart transplant: a case report. Am J Hematol. 2017;92:E34-5.

\section{Submit your next manuscript to BioMed Central and we will help you at every step:}

- We accept pre-submission inquiries

- Our selector tool helps you to find the most relevant journal

- We provide round the clock customer support

- Convenient online submission

- Thorough peer review

- Inclusion in PubMed and all major indexing services

- Maximum visibility for your research

Submit your manuscript at www.biomedcentral.com/submit
) Biomed Central 